\title{
Recrystallization of a Novel Two-Phase FeNiMnAlCr High Entropy Alloy
}

\author{
Ian Baker, Fanling Meng, Margaret Wu and André Brandenberg \\ 14 Engineering Dr., Dartmouth College, Hanover, NH 03755, U.S.A. \\ Corresponding author: Ian Baker; telephone number: 603-646-2184; email: \\ Ian.Baker@dartmouth.edu
}

\begin{abstract}
Cold rolling followed by annealing was performed on the as-cast, two-phase (f.c.c. + B2), lamellar-structured high entropy alloy $\mathrm{Fe}_{28.2} \mathrm{Ni}_{18.8} \mathrm{Mn}_{32.9} \mathrm{Al}_{14.1} \mathrm{Cr}_{6}$. The cold-rolled $\mathrm{Fe}_{28.2} \mathrm{Ni}_{18.8} \mathrm{Mn}_{32.9} \mathrm{Al}_{14.1} \mathrm{Cr}_{6}$ showed a very high yield strength of $1422 \mathrm{MPa}$ due to the high dislocation density (>1 $>10^{15} \mathrm{~m}^{-2}$ ), but only $2.3 \%$ elongation to failure. Annealing produced recrystallization, which caused the as-cast lamellar microstructure to be replaced by an equi-axed, duplex grain structure consisting of discrete B2 and f.c.c. grains with both different compositions and volume fractions. The recrystallized alloy showed a yield strength of $\sim 600 \mathrm{MPa}$ and an elongation of $\sim 20 \%$, which was only slightly different from the as-cast mechanical properties, a feature ascribed to the similarity in the scale $(0.5 \mu \mathrm{m})$ of the microstructure in the two states. It was found that although initial plastic deformation takes place in the f.c.c. phase, specimens either cold-rolled or strained to failure showed that both phases plastically deformed.
\end{abstract}

Keywords: Recrystallization, mechanical properties, microstructure, cold-working. 


\section{Introduction}

High-entropy alloys (HEAs), which are defined as single phase or multiphase alloys consisting of at least five elements with amounts in the range 5-35 at. \%, have been of growing interest over the last ten years for their sometimes superior mechanical properties [1-5]. Early investigations focused on alloying effects and phase transformation in various HEA systems. More recently, there have been a number of studies on the effects of cold rolling followed by a recrystallization anneal on either single phase or dual phase HEAs [6-10]. Otto et al. [6] annealed the single-phase f.c.c. HEA CoCrFeMnNi after different thickness reductions by cold rolling up to $96 \%$ and determined that the onset of recrystallization occurred at $873 \mathrm{~K}$, when the hardness dropped dramatically. Wu et al. [9, 10] examined the recrystallization of alloys of various combinations of the constituent elements of the HEA CoCrFeMnNi, and showed that the Cr-containing alloys in general were the strongest after recrystallizing to equi-axed grains. Later, Wu et al. showed that the addition of 0.5 at. \% carbon to FeNiCoCrMn increased the strain hardening rate and strength of the alloy after being cold rolled and recrystallized to produce a microstructure with equi-axed grains [11]. The recrystallization behavior of a 90\% cold-rolled two-phase (both phases were f.c.c.) HEA CoCrCuFeNi was studied by Park et al. [7], who observed fine-grain sizes around $1 \mu \mathrm{m}$ in the Cu-lean matrix after annealing at $973 \mathrm{~K}$, which produced recrystallization of the alloy: the microhardness decreased with increasing fraction recrystallized [7]. Tsai et al. [8] showed that cold rolling with a 50\% thickness reduction increased the hardness by $60 \%$ from that of the homogenized state for the two-phase (both phases were f.c.c.) HEA $\mathrm{Al}_{0.5} \mathrm{CoCrCuFeNi}$ due to an increase in nanotwin density. However, the strength increase was completely eliminated by annealing at $1173 \mathrm{~K}$ for $5 \mathrm{~h}$, which produced both recovery and recrystallization.

In this paper, we describe the effects of cold rolling and annealing on the microstructure and mechanical properties of the quinternary $\mathrm{HEA} \mathrm{Fe}_{28.2} \mathrm{Ni}_{18.8} \mathrm{Mn}_{32.9} \mathrm{Al}_{14.1} \mathrm{Cr}_{6}$, which in the ascast state consists of sub-micron scale alternating lamellae of f.c.c. and B2 (ordered b.c.c.) phases and shows a room temperature elongation to failure of $\sim 18 \%[12,13]$. It is worth noting that the room temperature deformation of the FeNiMnAl lamellar alloys [14] has some similarities to that of pearlitic steels in that at room temperature initial plastic deformation only occurs in the softer matrix (f.c.c.) phase $[15,16]$. 


\section{Experimental}

$60 \mathrm{~g}$ ingots of $\mathrm{Fe}_{28.2} \mathrm{Ni}_{18.8} \mathrm{Mn}_{32.9} \mathrm{Al}_{14.1} \mathrm{Cr}_{6}$ were arc-melted from pieces of $99.8 \% \mathrm{Fe}, 99.95 \% \mathrm{Ni}$, 99.8\% $\mathrm{Mn}$ and $99.8 \% \mathrm{Al}$ and $99.8 \% \mathrm{Cr}$ in a water-chilled copper crucible under an argon atmosphere: an additional 5 wt. \% Mn was added to the reactants to compensate for the loss of manganese due to evaporation during processing. Ingots were flipped and re-melted twice after the initial melting to ensure homogeneous mixing. The grain size of the as-cast material was $450 \pm 50 \mu \mathrm{m}[17]$.

Blocks were machined from the ingots to a thickness of $\sim 6 \mathrm{~mm}$, and cold-rolled to a rolling reduction of $\sim 65 \%$ using a two-high, 4.2 " rolling mill with a small reduction $(\sim 5 \%)$ per pass and then annealed at $1273 \mathrm{~K}$ for $1 \mathrm{~h}$.

Specimens were examined before rolling, and after rolling and annealing in both a FEI XL-30 field emission gun (FEG) scanning electron microscope (SEM) operated at $15 \mathrm{kV}$ and a FEI Tecnai F20 FEG transmission electron microscope (TEM) equipped with energy dispersive X-ray spectrometry (EDS) operated at $200 \mathrm{kV}$. Electron microscope observations were performed on both the undeformed and strained alloys. Details of specimen preparation for both SEM and TEM observation can be found elsewhere $[14,16]$.

Dislocation densities were determined by drawing lines on the TEM images and counting the number of dislocations that intercept the lines [18]. The line length was also measured with ImageJ. In both cases a foil thickness of $100 \mathrm{~nm}$ was assumed.

Tensile tests were performed on the cold-rolled and annealed alloy using flat dog-bone tensile specimens with a gauge length of $10 \mathrm{~mm}$, a width of $2.54 \mathrm{~mm}$ and a thickness of $\sim 1.27$ $\mathrm{mm}$. The specimens were polished to a mirror finish using various grades of silicon carbide papers followed by polishing with $0.3 \mu \mathrm{m}$ alumina powder. Tensile tests were performed at an

initial strain rate of $5 \times 10^{-4} \mathrm{~s}^{-1}$ at room temperature. The elongation to failure was determined from measurements of the gauge length before and after testing. The resulting fracture surfaces were examined using secondary electron imaging in the SEM, and the specimens strained to failure were examined in the TEM.

\section{Results}


As shown in the secondary (SE) and bright field TEM images in Figures 1 (a) and (b), as-cast $\mathrm{Fe}_{28.2} \mathrm{Ni}_{18.8} \mathrm{Mn}_{32.9} \mathrm{Al}_{14.1} \mathrm{Cr}_{6}$ consists of alternating lamellae of an f.c.c. and a $\mathrm{B} 2$ phases: the light phase in the SE image is the B2 phase. The average lamellae widths, measured from SE images using the line intercept, were $\sim 400 \mathrm{~nm}$ for the f.c.c. phase and $\sim 200 \mathrm{~nm}$ for the B2 phase. However, there were wide variations in the lamellae widths, e.g. measurements of the widths of the f.c.c. phase ranged from $240 \mathrm{~nm}$ to $480 \mathrm{~nm}$. Analysis of the SE image showed that the volume fractions of the f.c.c. and B2 phases were 0.65 and 0.35 , respectively. The selected area diffraction (SAD) patterns in Figure 1 (c) and (d) confirm that the two phases are B2 and f.c.c. The results of EDS on the two phases are shown in Table 1. The f.c.c. phase is enriched in Fe, $\mathrm{Mn}$ and $\mathrm{Cr}$ and the B2 phase is enriched in $\mathrm{Ni}$ and Al. Note that the f.c.c. phase could be considered to be a high entropy phase.

Figure 2 shows SE images of a longitudinal section of the alloy after cold rolling to an $\sim 65 \%$ rolling reduction. Previous work has shown that initial plastic deformation at room temperature occurs only in the f.c.c. phase in lamellar-structured f.c.c./B2 FeNiMnAlCr alloys [12]. However, since there is no cracking evident, plastic deformation must have also occurred in the B2 phase. Since the B2 phase is harder than the f.c.c. phase [19] presumably initial plastic deformation takes place in the f.c.c. phase until it work hardens to the point where the flow stress equals the yield strength of the B2 phase, at which point the latter also starts to plastically deform.

Figure 3 is a bright field TEM image taken perpendicular to the rolling plane of the coldrolled specimen. This shows very high dislocation densities in both the B2 and the f.c.c. phases in which little recovery has occurred. The dislocation densities are so large that individual dislocations are unresolvable, which is typical of materials deformed to high rolling strains [20], where dislocation densities are $>1 \times 10^{15} \mathrm{~m}^{-2}$.

Backscattered electron (BSE) imaging of the alloy after cold-rolling to a $65 \%$ thickness reduction and annealing at $1273 \mathrm{~K}$ for $1 \mathrm{~h}$, see Figure 4(a), shows an equi-axed grain structure the dark areas are the B2 phase and the lighter areas are the f.c.c. phase. After recrystallization the volume fractions of the phases had changed slightly with the f.c.c. volume fraction increasing to 0.71 (from 0.65 in the as-cast state). Interestingly, simply annealing for $1 \mathrm{~h}$ at $1273 \mathrm{~K}$ produces a slight coarsening of the microstructure (compare Figure 5 and Figure 1a) and a decrease in the volume fraction of the f.c.c. phase to 0.55 (from 0.65 in the as-cast state). 
Figure 4(b) is a bright field TEM micrograph after cold-rolling to a $65 \%$ rolling reduction and annealing at $1273 \mathrm{~K}$ for $1 \mathrm{~h}$, which again shows that the alloy had recrystallized to equi-axed grains. Figures 4(c, d) are SAD patterns identifying some grains as B2 and some as f.c.c. The grain sizes of the two phases are $\sim 0.5 \mu \mathrm{m}$. Figure 6 is a higher magnification bright field TEM image of $\mathrm{Fe}_{28.2} \mathrm{Ni}_{18.8} \mathrm{Mn}_{32.9} \mathrm{Al}_{14.1} \mathrm{Cr}_{6}$ cold rolled and annealed for $1 \mathrm{~h}$ at $1273 \mathrm{~K}$. Examination of over 40 TEM images of the recrystallized material found only the few dislocations in the f.c.c. grains (dislocation density of $2.4 \times 10^{12} \mathrm{~m}^{-2}$ ) in a single image, shown in Figure 6. No residual dislocations were found in any B2 grains. EDS performed in the TEM shows a small change in chemistry of both phases compared to the lamellae-structured as-cast $\mathrm{Fe}_{28.2} \mathrm{Ni}_{18.8} \mathrm{Mn}_{32.9} \mathrm{Al}_{14.1} \mathrm{Cr}_{6}$, see Table 1, with the B2 phase becoming richer in Fe and Mn and having a lower concentration of Al.

Figure 7 shows typical stress strain curves from specimens tensile tested at a strain rate of $5 \times 10^{-4} \mathrm{~s}^{-1}$ for $\mathrm{Fe}_{28.2} \mathrm{Ni}_{18.8} \mathrm{Mn}_{32.9} \mathrm{Al}_{14.1} \mathrm{Cr}_{6}$ in the as-cast condition, after cold rolling, and after cold rolling and annealing (the initial upward curvature is due to the tightening of the load train). Table 2 shows the average results from three tensile tests of both the cold-rolled material and the recrystallized material; previously determined values for the as-cast material are shown for comparison [12]. The cold-rolled $\mathrm{Fe}_{28.2} \mathrm{Ni}_{18.8} \mathrm{Mn}_{32.9} \mathrm{Al}_{14.1} \mathrm{Cr}_{6}$ shows a very high yield stress of $1442 \mathrm{MPa}$, which is about twice the value for that of as-cast material. However, the cold rolling also decreased the elongation significantly from $17.8 \%$ for as-cast material to $2.3 \%$. On the other hand, the recrystallized $\mathrm{Fe}_{28.2} \mathrm{Ni}_{18.8} \mathrm{Mn}_{32.9} \mathrm{Al}_{14.1} \mathrm{Cr}_{6}$ shows a little higher elongation than as-cast material with a corresponding slight reduction in yield stress (from $679 \mathrm{MPa}$ to $599 \mathrm{MPa}$ ).

Figure 8 shows a comparison of the fracture surfaces for the as-cast, cold rolled, and recrystallized $\mathrm{Fe}_{28.2} \mathrm{Ni}_{18.8} \mathrm{Mn}_{32.9} \mathrm{Al}_{14.1} \mathrm{Cr}_{6}$ after being tensile tested at a strain rate of $5 \times 10^{-4} \mathrm{~s}^{-1}$, where ductile fracture with dimples was observed in all cases. The size of the dimples in the recrystallized material is $\sim 1 \mu \mathrm{m}$ in diameter, which is greater than those observed in either the ascast or the cold-rolled material, which is consistent with the greater elongation observed in the recrystallized material. It's worth noting that Trybus et al. showed that the dimples became smaller and shallower with increasing thickness reduction in cold rolling, where the decreasing dimple sizes correspond to the decreasing average spacing with higher rolling deformation [21].

TEM examination of the recrystallized $\mathrm{Fe}_{28.2} \mathrm{Ni}_{18.8} \mathrm{Mn}_{32.9} \mathrm{Al}_{14.1} \mathrm{Cr}_{6}$ strained to failure showed that deformation took place in both the f.c.c. and B2 phases, see Figure 9. The measured 
dislocation densities after failure were $3.0 \times 10^{14} \mathrm{~m}^{-2}$ for the f.c.c. phase (Figure 9a) and $1.8 \mathrm{x}$ $10^{14} \mathrm{~m}^{-2}$ for the B2 phase (Figure $9 \mathrm{~b}$ ).

\section{Discussion}

Similar to the observation here of a $0.5 \mu \mathrm{m}$ recrystallized grain size in $\mathrm{Fe}_{28.2} \mathrm{Ni}_{18.8} \mathrm{Mn}_{32.9} \mathrm{Al}_{14.1} \mathrm{Cr}_{6}$, a very fine microstructure with average recrystallized grain size $\sim 1 \mu \mathrm{m}$ was found after annealing the cold-rolled HEA CoCrFeMnNi at $650^{\circ} \mathrm{C}$ for $1 \mathrm{~h}$ [22]. The low grain growth and fine-grained structure of $\mathrm{CoCrFeMnNi}$ was attributed to the whole-solute distorted matrix, which is a feature of the high lattice distortion energy, sluggish diffusion effect and low stacking fault energy [22]. Otto et al. [6] showed that the grain size of this alloy increased with increasing annealing temperature as is typical of most metallic materials. The fine recrystallized grain size in the alloy investigated here, $\mathrm{Fe}_{28.2} \mathrm{Ni}_{18.8} \mathrm{Mn}_{32.9} \mathrm{Al}_{14.1} \mathrm{Cr}_{6}$, could also be due to sluggish diffusion, but it could also be because it is two-phase alloy with one phase limiting the growth of the other phase.

There has been relatively little work on recrystallization of coarse two-phase alloys, i.e. alloys that contain large volume fractions (0.2-0.8 [23]) of each phase. Recrystallization of such coarse two-phase alloys is the most closely related to recrystallization of $\mathrm{Fe}_{28.2} \mathrm{Ni}_{18.8} \mathrm{Mn}_{32.9} \mathrm{Al}_{14.1} \mathrm{Cr}_{6}$ [23-30]. In fact, recrystallization of cold-worked $\alpha+\beta$ brass may have the greatest similarly since that material consists of a f.c.c. $\alpha$ phase containing $\sim 37$ at. $\% \mathrm{Zn}$ and a B2 $\beta$ phase containing $\sim 9$ at. $\% \mathrm{Zn}$ at room temperature. For $\alpha+\beta$ brass, the $\alpha$ phase deforms before the $\beta$ phase because it is softer [24], but eventually at higher strains both phases deform - as observed for the $\mathrm{Fe}_{28.2} \mathrm{Ni}_{18.8} \mathrm{Mn}_{32.9} \mathrm{Al}_{14.1} \mathrm{Cr}_{6}$ studied here. The simplest situation is if the $\alpha+\beta$ brass is annealed at the temperature at which it was equilibriated. In that case, the recrystallization behavior depends on the strain. For strains below $40 \%$, recrystallization occurs first in the $\beta$ phase while the $\alpha$ phase undergoes recovery and eventually undergoes recrystallization starting at the $\alpha / \beta$ interface [25]. This behavior appears to reflect the low stacking fault energy of the $\alpha$ phase and the high stacking fault energy of the $\beta$ phase. The latter enables rapid dislocation rearrangement into subgrains and their coalescence to form recrystallization nuclei in the $\beta$ phase, and, hence, its faster recrystallization. At strains above $70 \%$, the $\beta$ phase undergoes a strain-induced martensitic phase transformation and the behavior becomes more complicated [25]. The recrystallization behavior is also more complicated if the 
recrystallization anneal is carried out at a temperature different to the temperature at which the $\alpha$ $+\beta$ brass was equilibriated. A typical consequence for this situation is that the volume fractions of the phases are different before and after recrystallization, which is the situation observed here for $\mathrm{Fe}_{28.2} \mathrm{Ni}_{18.8} \mathrm{Mn}_{32.9} \mathrm{Al}_{14.1} \mathrm{Cr}_{6}$. Differences in the compositions of the phases are also likely to occur, again as observed in the current study.

Turning to the mechanical properties, the large increase in yield strength and reduction in elongation to failure upon cold rolling is due to the observed large increase in dislocation density, and such behavior has been observed in other HEAs. [31]. The decrease in the yield strength in the recrystallized $\mathrm{Fe}_{28.2} \mathrm{Ni}_{18.8} \mathrm{Mn}_{32.9} \mathrm{Al}_{14.1} \mathrm{Cr}_{6}$ compared to the as-cast material is probably because the grain size was slightly larger $(0.5 \mu \mathrm{m})$ than the width of the f.c.c. lamellae $(0.4 \mu \mathrm{m})$ in the ascast material, i.e. the slight softening is likely due to microstructural coarsening rather than a change in the morphology or composition of the phases. Previously, it has been shown that during room-temperature straining of lamellar-structured FeNiMnAl alloys, initial plastic deformation only occurred in the f.c.c. phase, with slip being quite planar, leading to pile-ups at grain boundaries at temperatures up to at least $900 \mathrm{~K}$ [16]. This pile-up behavior leads to a yield strength dependence on the f.c.c. lamellae spacing, $\lambda$, of $\lambda^{-1}[16]$, a relationship that also appears to describe some pearlitic steels [30,31] where plastic deformation occurs only in the ferrite phase.

As noted earlier, dislocations were found in both B2 and f.c.c. phases both after coldrolling and after straining to failure of the recrystallized $\mathrm{Fe}_{36} \mathrm{Ni}_{18} \mathrm{Mn}_{33} \mathrm{Al}_{13}$. This again indicates that while initial deformation occurs only in the f.c.c. phase because it is softer [32], workhardening of this phase eventually leads to plastic deformation in the B2 phase.

\section{Conclusions}

A cold rolling reduction of $65 \%$ performed on the two-phase (f.c.c. + B2) lamellar-structured HEA $\mathrm{Fe}_{28.2} \mathrm{Ni}_{18.8} \mathrm{Mn}_{32.9} \mathrm{Al}_{14.1} \mathrm{Cr}_{6}$ produced a large yield strength (1442 $\mathrm{MPa}$ ) but a low elongation to failure $(2.3 \%)$ compared to the as-cast material (679 $\mathrm{MPa}, 17.8 \%)$. Annealing the coldworked material at $1273 \mathrm{~K}$ for $1 \mathrm{~h}$ leads to recrystallization in which the lamellar structure is replaced by a micron-scale equi-axed grain structure consisting of discrete B2 and f.c.c. grains, which have both different volume fractions and different compositions compared to the as-cast 
material. The recrystallized material shows a lower, but still good, yield strength (600 MPa) and slightly higher elongation to failure $(19.5 \%)$ compared to the as-cast material.

\section{Acknowledgments}

This research was supported by the US Department of Energy (DOE), Office of Basic Energy Sciences grant DE-FG02-07ER46392. The views and conclusions contained herein are those of the authors and should not be interpreted as necessarily representing official policies, either expressed or implied of the DOE or the U.S. Government. 


\section{References}

[1]. J.W. Yeh, S.K. Chen, S.J. Lin, J.Y. Gan, T.S. Chin, T.T. Shun, C.H. Tsau, and S.Y. Chang, Nanostructured High-Entropy Alloys with Multiple Principal Elements: Novel Alloy Design Concepts and Outcomes. Advanced Engineering Materials, 2004. 6(5): p. 299-303. DOI: 10.1002/adem.200300567

[2]. A. Gali and E.P. George, Tensile properties of high-and medium-entropy alloys. Intermetallics, 2013. 39(0): p. 74-78. doi:10.1016/j.intermet.2013.03.018

[3]. F. Otto, A. Dlouhý, C. Somsen, H. Bei, G. Eggeler, and E.P. George, The influences of temperature and microstructure on the tensile properties of a CoCrFeMnNi high-entropy alloy. Acta Materialia, 2013. 61(15): p. 5743-5755. doi:10.1016/j.actamat.2013.06.018

[4]. F. Otto, Y. Yang, H. Bei, and E.P. George, Relative effects of enthalpy and entropy on the phase stability of equiatomic high-entropy alloys. Acta Materialia, 2013. 61(7): p. 26282638. doi:10.1016/j.actamat.2013.01.042

[5]. K.Y. Tsai, M.H. Tsai, and J.W. Yeh, Sluggish diffusion in $\mathrm{Co}-\mathrm{Cr}-\mathrm{Fe}-\mathrm{Mn}-\mathrm{Ni}$ highentropy alloys. Acta Materialia, 2013. 61(13): p. 4887-4897.

doi:10.1016/j.actamat.2013.01.042

[6]. F. Otto, N.L. Hanold, and E.P. George, Microstructural evolution after thermomechanical processing in an equiatomic, single-phase CoCrFeMnNi high-entropy alloy with special focus on twin boundaries. Intermetallics, 2014. 54: p. 39-48. doi:10.1016/j.intermet.2014.05.014

[7]. N. Park, I. Watanabe, D. Terada, Y. Yokoyama, P. Liaw, and N. Tsuji, Recrystallization Behavior of CoCrCuFeNi High-Entropy Alloy. Metallurgical and Materials Transactions A, 2014. 46A: p. 1-7. doi: 10.1007/s11661-014-2594-5

[8]. C.-W. Tsai, Y.-L. Chen, M.-H. Tsai, J.-W. Yeh, T.-T. Shun, and S.-K. Chen, Deformation and annealing behaviors of high-entropy alloy Al $0.5 \mathrm{CoCrCuFeNi}$. Journal of Alloys and Compounds, 2009. 486(1): p. 427-435. doi:10.1016/j.jallcom.2009.06.182

[9]. Z. Wu, H. Bei, F. Otto, G.M. Pharr, and E.P. George, Recovery, Recrystallization, Grain Growth and Phase Stability of a Family of FCC-Structured Multi-Component Equiatomic Solid Solution Alloys. Intermetallics, 2014. 46: p.131-140. doi:10.1016/j.intermet.2013.10.024

[10]. Z. Wu, H. Bei, G.M. Pharr, and E.P. George, Temperature dependence of the mechanical properties of equiatomic solid solution alloys with face-centered cubic crystal structures. Acta Materialia, 2014. 81: p. 428-441. doi:10.1016/j.actamat.2014.08.026 
[11]. Z. Wu, C.M. Parish, and H. Bei, Nano-twin Mediated Plasticity in Carbon-containing FeNiCoCrMn High Entropy Alloys. Journal of Alloys and Compounds, 2015. 647: p. 815-822. doi:10.1016/j.jallcom.2015.05.224

[12]. F. Meng, J. Qiu, and I. Baker, The effects of chromium on the microstructure and tensile behavior of $\mathrm{Fe}_{30} \mathrm{Ni}_{20} \mathrm{Mn}_{35} \mathrm{Al}_{15}$. Materials Science and Engineering A, 2013. 586: p. 45-52. doi:10.1016/j.msea.2013.08.005

[13]. F. Meng, S.F. Bauer, Y. Liao, and I. Baker, Concentration dependence of Cr for alleviating environmental embrittlement in $\mathrm{Fe}_{30} \mathrm{Ni}_{20} \mathrm{Mn}_{35} \mathrm{Al}_{15}$. Intermetallics, 2015. 56: $\mathrm{p}$. 28-32. doi:10.1016/j.intermet.2014.08.007

[14]. F. Meng, J. Qiu, and I. Baker, Effect of Al content on the microstructure and mechanical behavior of two-phase FeNiMnAl alloys. Journal of Materials Science, 2014. 49(5): p. 1973-1983. doi: 10.1007/s10853-013-7884-6

[15]. K.Y. Lee, Y.R. Im, L.A.I. Kestens, and G.S. Kim, Recrystallization and Spheroidization Behavior of High Carbon Pearlitic Steels Investigated by Means of Orientation Imaging Microscopy. Materials Science Forum, 2007. 539-543: p. 4556-4561 doi: 10.4028/www.scientific.net/MSF.539-543.4556

[16]. Y. Liao and I. Baker, Evolution of the microstructure and mechanical properties of eutectic $\mathrm{Fe}_{30} \mathrm{Ni}_{20} \mathrm{Mn}_{35} \mathrm{Al}_{15}$. Journal of Materials Science, 2011. 46(7): p. 2009-2017. doi: 0.1007/s10853-010-5197-6

[17] F. Meng, S.F. Bauer, Y. Liao and I. Baker, Concentration Dependence of Cr for Alleviating Environmental Embrittlement in $\mathrm{Fe}_{30} \mathrm{Ni}_{20} \mathrm{Mn}_{35} \mathrm{Al}_{15}$, Intermetallics, 56 (2015) 28-32.

[18] D.B. Willams and C.B. Carter Transmission Electron Microscopy, 1996, Plenum Press, New York.

[19]. Y. Liao and I. Baker, On the Room-Temperature Deformation Mechanisms of LamellarStructured $\mathrm{Fe}_{30} \mathrm{Ni}_{20} \mathrm{Mn}_{35} \mathrm{Al}_{15}$. Materials Science and Engineering, 2011. A 528: p. 3998 4008. doi:10.1016/j.msea.2011.01.089

[20] S. C. Wang, Z. Zhu and M. J. Starink, "Estimation of dislocation densities in cold rolled Al-Mg-Cu-Mn alloys by combination of yield strength data, EBSD and strength models", Journal of Microscopy, 2005, 217, p174-178.

[21]. C.L. Trybus and W.A. Spitzig, Characterization of the strength and microstructural evolution of a heavily cold rolled Cu-20\% Nb composite. Acta Metallurgica, 1989. 37(7): p. 1971-1981. doi:10.1016/0001-6160(89)90081-3 
[22] P. Bhattacharjee, G. Sathiaraj, M. Zaid, J. Gatti, C. Lee, C.-W. Tsai, and J.-W. Yeh, Microstructure and texture evolution during annealing of equiatomic CoCrFeMnNi highentropy alloy. Journal of Alloys and Compounds, 2014. 587: p. 544-552. doi:10.1016/j.jallcom.2013.10.237

[23] E. Hornbogen, "Recrystallization of Coarse Two-Phase Alloys", $1^{\text {st }}$ Ris $\emptyset$ International Symposium on Metallurgy and Materials Science, Recrystallization and Grain Growth of Multi-Phase and Particle Containing Materials (Ed- N. Hansen, A.R. Jones and T. Leffers) 1980. p.199-209.

[24] R.W.K. Honeycombe and W. Boas, The Deformation and Recrystallization of an Alloy containing Two Phases. Australian Journal of Scientific Research, 1948. A1: p.70-76.

[25] K. Mäder and E. Hornbogen, Systematics of Recrystallization in $\alpha+\beta$ Brass. Scripta Metallurgica, 1974. 8: p. 979-984. doi:10.1016/0036-9748(74)90396-2

[26] R. Garg, S. Ranganathan and S. Suwas, Effect of mode of rolling on development of texture and microstructure in two-phase $(\alpha+\beta)$ brass. Materials Science and Engineering A, 2010, 527: p. 4582-4592. doi:10.1016/j.msea.2010.04.012

[27] E. Hornbogen and U. Koster, in Recrystallization of Metallic Materials (Ed - F. Haessner) 1978. p159.

[28] B.A. Cooke and B. Ralph, "Recrystallization of Coarse Two-Phase Alloys" $1^{\text {st }}$ Ris $\varnothing$ International Symposium on Metallurgy and Materials Science, Recrystallization and Grain Growth of Multi-Phase and Particle Containing Materials (Ed- N. Hansen, A.R. Jones and T. Leffers) 1980. p. 211-216.

[29] L.M. Clarebrough, Deformation and Recrystallization of Alloys containing Two Phases. Australian Journal of Scientific Research, 1950. A3(1): p. 72-90.

[30] A.K. Vasudevan. J.J. Petrovic and J.A. Roberson, Recrystallization Behavior of a Model Two-Phase Alloy, Ag-Ni. Scripta Metallurgica, 1974. 8: p. 861-868. doi:10.1016/00369748(74)90307-X

[31] M.J. Yao, K.G. Pradeep, C.C. Tasan and D. Raabe, A novel, single phase, nonequiatomic FeMnNiCoCr high-entropy alloy with exceptional phase stability and tensile ductility. Scripta Materialia, 2014, 72-73: p. 5-8. doi:10.1016/j.scriptamat.2013.09.030

[32] J. Šašková and A. Kř́žž, Study of recrystallization behavior of thermomechanically processed steels in Metal 2010: Rožnov pod Radhoštěm, Česká Republika, p.18-20. 


\section{FIGURE CAPTIONS}

Figure 1. (a) Secondary electron, and (b) bright Field TEM image of as-cast $\mathrm{Fe}_{28.2} \mathrm{Ni}_{18.8} \mathrm{Mn}_{32.9} \mathrm{Al}_{14.1} \mathrm{Cr}_{6}$ showing lamellar microstructure consisting of alternating f.c.c. and B2 phases. (c) and (d) are corresponding selected area diffraction patterns from the B2 and f.c.c. phases, respectively. The lighter areas are the B2 phase in the SE image.

Figure 2. SE images of a longitudinal section of $\mathrm{Fe}_{28.2} \mathrm{Ni}_{18.8} \mathrm{Mn}_{32.9} \mathrm{Al}_{14.1} \mathrm{Cr}_{6}$ after cold rolling: the lighter areas are the B2 phase. The rolling direction (RD) is indicated.

Figure 3. BF TEM image of of $\mathrm{Fe}_{28.2} \mathrm{Ni}_{18.8} \mathrm{Mn}_{32.9} \mathrm{Al}_{14.1} \mathrm{Cr}_{6}$ after cold rolling viewed perpendicular to the rolling plane.

Figure 4. (a) BSE image (the lighter areas are the f.c.c. phase), and (b) bright field TEM image of $\mathrm{Fe}_{28.2} \mathrm{Ni}_{18.8} \mathrm{Mn}_{32.9} \mathrm{Al}_{14.1} \mathrm{Cr}_{6}$ cold rolled and annealed for $1 \mathrm{~h}$ at $1273 \mathrm{~K}$ showing equi-axed grains of the f.c.c. (light) and B2 (dark) phases. SAD patterns from (c) an f.c.c. grain, and (d) a B2 grain are also shown. The crystal structures of the grains marked in (b) were identified from their electron diffraction patterns.

Figure 5. SE images of $\mathrm{Fe}_{28.2} \mathrm{Ni}_{18.8} \mathrm{Mn}_{32.9} \mathrm{Al}_{14.1} \mathrm{Cr}_{6}$ after annealing at $1273 \mathrm{~K}$ for $1 \mathrm{~h}$ : the lighter areas are the $\mathrm{B} 2$ phase.

Figure 6. Higher magnification bright field TEM image of $\mathrm{Fe}_{28.2} \mathrm{Ni}_{18.8} \mathrm{Mn}_{32.9} \mathrm{Al}_{14.1} \mathrm{Cr}_{6}$ cold rolled and annealed for $1 \mathrm{~h}$ at $1273 \mathrm{~K}$ showing a few dislocations in the f.c.c. grains.

Figure 7. Typical stress-strain curves for as-cast, cold rolled, and recrystallized $\mathrm{Fe}_{28.2} \mathrm{Ni}_{18.8} \mathrm{Mn}_{32.9} \mathrm{Al}_{14.1} \mathrm{Cr}_{6}$. The curve for as-cast material is taken from [12].

Figure 8. Secondary electron images showing the fracture surfaces of $\mathrm{Fe}_{28.2} \mathrm{Ni}_{18.8} \mathrm{Mn}_{32.9} \mathrm{Al}_{14.1} \mathrm{Cr}_{6}$ after tensile testing in (a) the as-cast state, (b) after cold-rolling, and (c) after recrystallization.

Figure 9. Bright Field TEM images from (a) the f.c.c. phase, and (b) the B2 phase of recrystallized $\mathrm{Fe}_{28.2} \mathrm{Ni}_{18.8} \mathrm{Mn}_{32.9} \mathrm{Al}_{14.1} \mathrm{Cr}_{6}$ after straining to failure, accompanied by $\mathrm{SAD}$ patterns from the corresponding phases. Dislocations were present in both the f.c.c. and B2 phases. 
Table 1. Compositions (in at. \%) of phases of as-cast, and in cold-worked (CW) and annealed $\mathrm{Fe}_{28.2} \mathrm{Ni}_{18.8} \mathrm{Mn}_{32.9} \mathrm{Al}_{14.1} \mathrm{Cr}_{6}$, as determined from EDS measurements in a TEM. The error bars indicated the standard deviations from five measurements.

\begin{tabular}{|c|c|c|c|c|c|c|}
\hline State & Phase & Fe & Ni & Mn & Al & Cr \\
\hline \multirow{2}{*}{ As-cast } & f.c.c. & $36.4 \pm 1.2$ & $14.1 \pm 0.3$ & $33.4 \pm 0.6$ & $10.3 \pm 0.5$ & $6.4 \pm 0.1$ \\
\cline { 2 - 7 } & B2 & $5.9 \pm 1.0$ & $40.6 \pm 0.4$ & $15.3 \pm 0.7$ & $37.2 \pm 1.5$ & $1.0 \pm 0.2$ \\
\hline $\begin{array}{c}\text { CW }+ \\
\text { annealed }\end{array}$ & f.c.c. & $34.4 \pm 0.5$ & $12.8 \pm 0.3$ & $32.9 \pm 0.3$ & $11.6 \pm 0.3$ & $6.4 \pm 0.1$ \\
\cline { 2 - 7 } & B2 & $8.2 \pm 1.4$ & $40.8 \pm 1.3$ & $20.8 \pm 0.9$ & $29.2 \pm 0.6$ & $1.2 \pm 0.4$ \\
\hline
\end{tabular}

Table 2. Yield strength, ultimate tensile strength (UTS) and elongation to failure for as-cast and for cold-worked $(\mathrm{CW})$ and annealed $\mathrm{Fe}_{28.2} \mathrm{Ni}_{18.8} \mathrm{Mn}_{32.9} \mathrm{Al}_{14.1} \mathrm{Cr}_{6}$ tensile tested at $5 \times 10^{-4} \mathrm{~s}^{-1}$. The error bars indicated the standard deviations from three tests. Data for as-cast materials are taken from [12].

\begin{tabular}{|c|c|c|c|}
\hline Material state & Elongation (\%) & Yield stress (MPa) & UTS (MPa) \\
\hline as-cast & $17.8 \pm 0.2$ & $679 \pm 25$ & $931 \pm 3$ \\
\hline CW & $2.3 \pm 0.3$ & $1442 \pm 35$ & $1521 \pm 33$ \\
\hline CW + annealed & $19.5 \pm 1.4$ & $599 \pm 22$ & $868 \pm 10$ \\
\hline
\end{tabular}



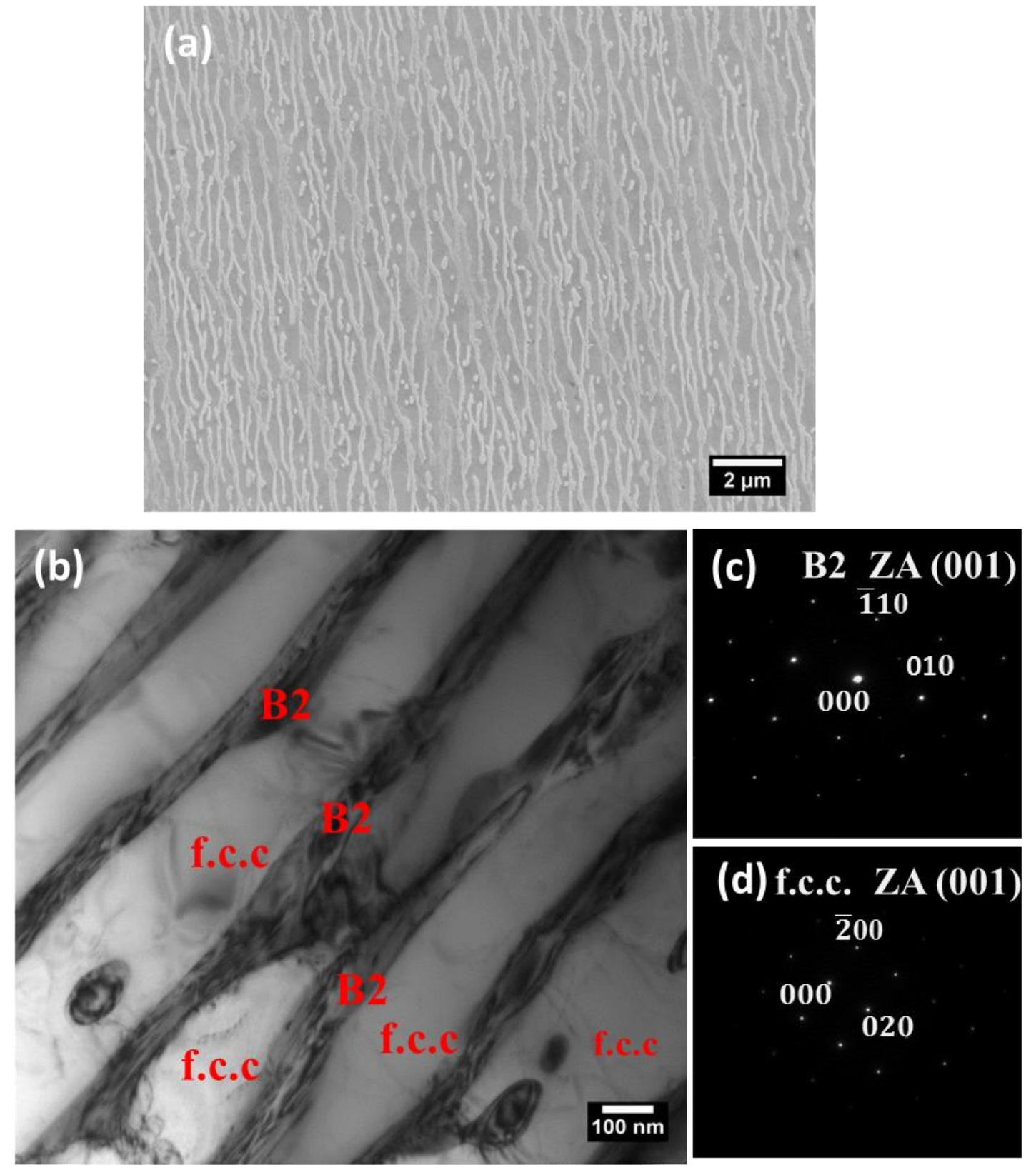

Figure 1. (a) Secondary electron, and (b) bright Field TEM image of as-cast $\mathrm{Fe}_{28.2} \mathrm{Ni}_{18.8} \mathrm{Mn}_{32.9} \mathrm{Al}_{14.1} \mathrm{Cr}_{6}$ showing lamellar microstructure consisting of alternating f.c.c. and $\mathrm{B} 2$ phases. (c) and (d) are corresponding selected area diffraction patterns from the B2 and f.c.c. phases, respectively. The lighter areas are the B2 phase in the SE image. 


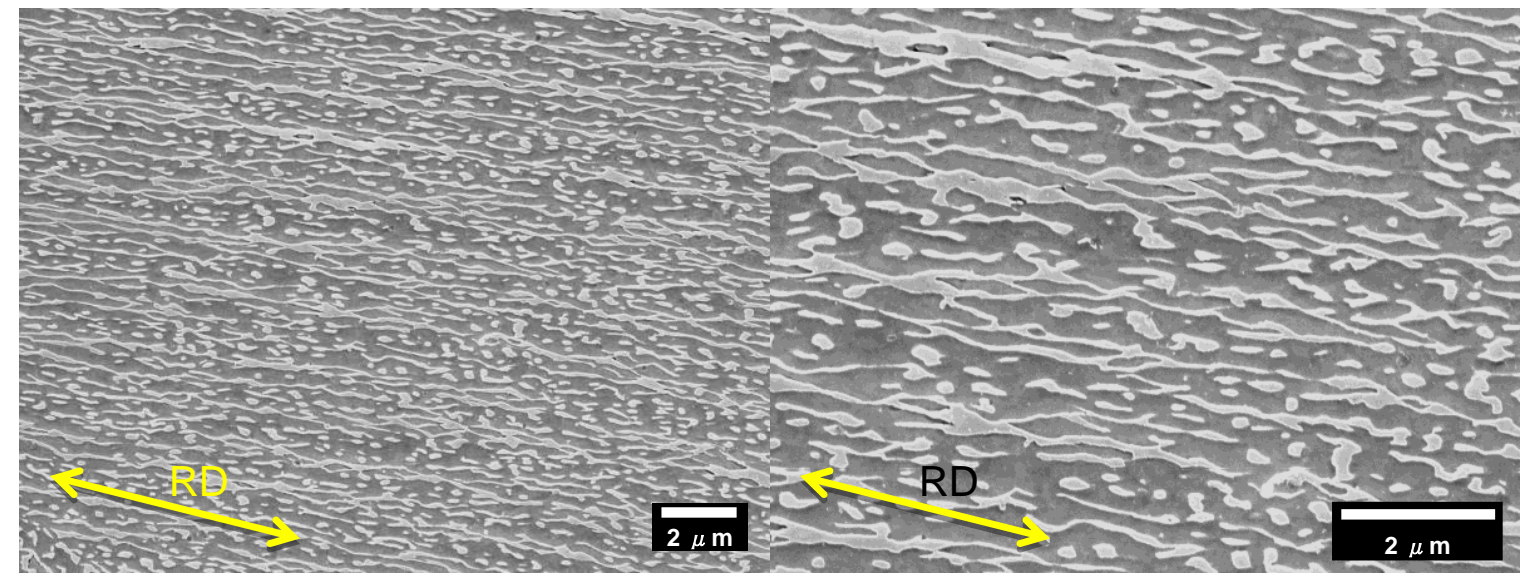

Figure 2. SE images of a longitudinal section of $\mathrm{Fe}_{28.2} \mathrm{Ni}_{18.8} \mathrm{Mn}_{32.9} \mathrm{Al}_{14.1} \mathrm{Cr}_{6}$ after cold rolling: the lighter areas are the $\mathrm{B} 2$ phase. The rolling direction (RD) is indicated. 


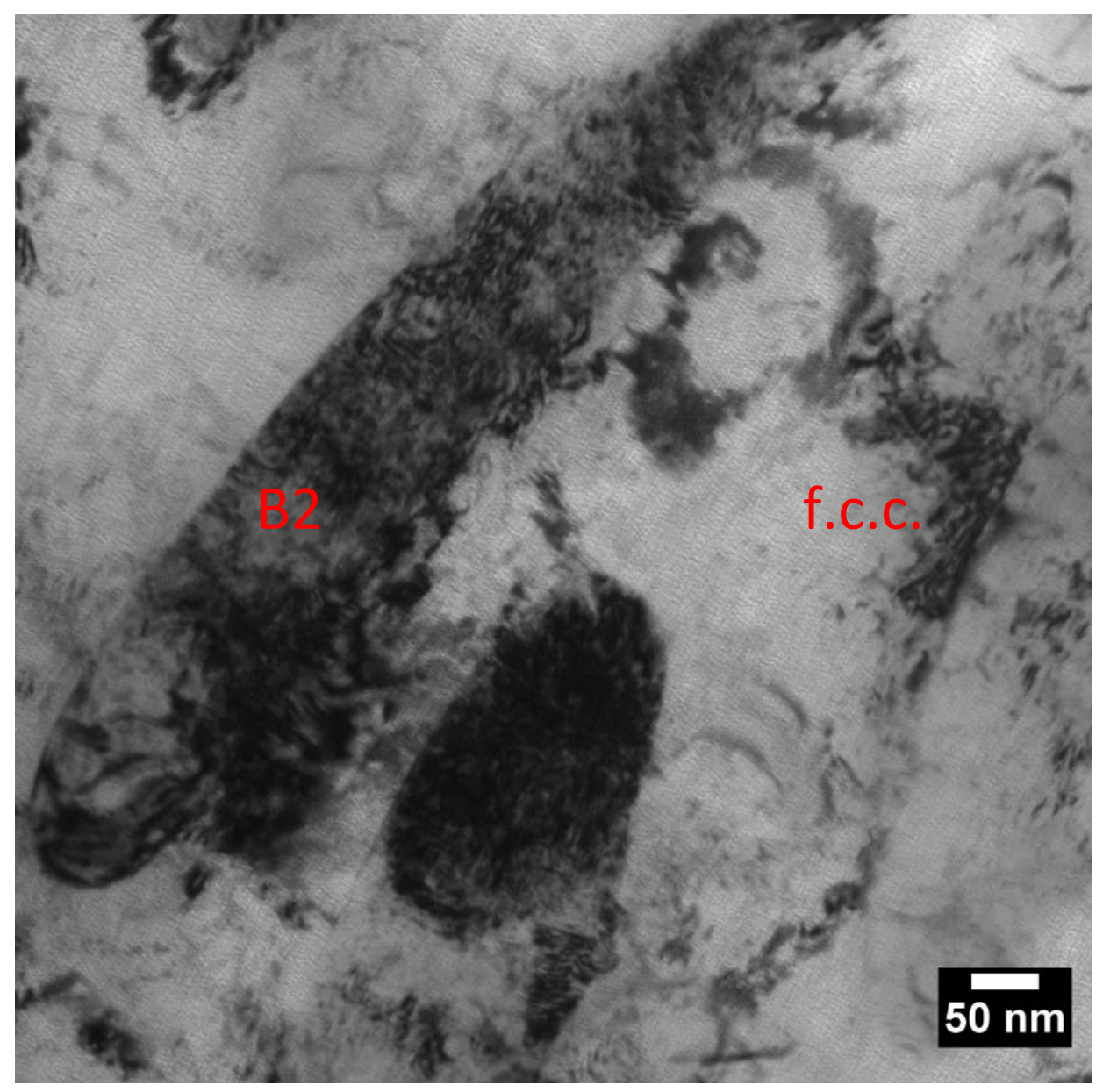

Figure 3. Bright field TEM image of of $\mathrm{Fe}_{28.2} \mathrm{Ni}_{18.8} \mathrm{Mn}_{32.9} \mathrm{Al}_{14.1} \mathrm{Cr}_{6}$ after cold rolling viewed perpendicular to the rolling plane. 

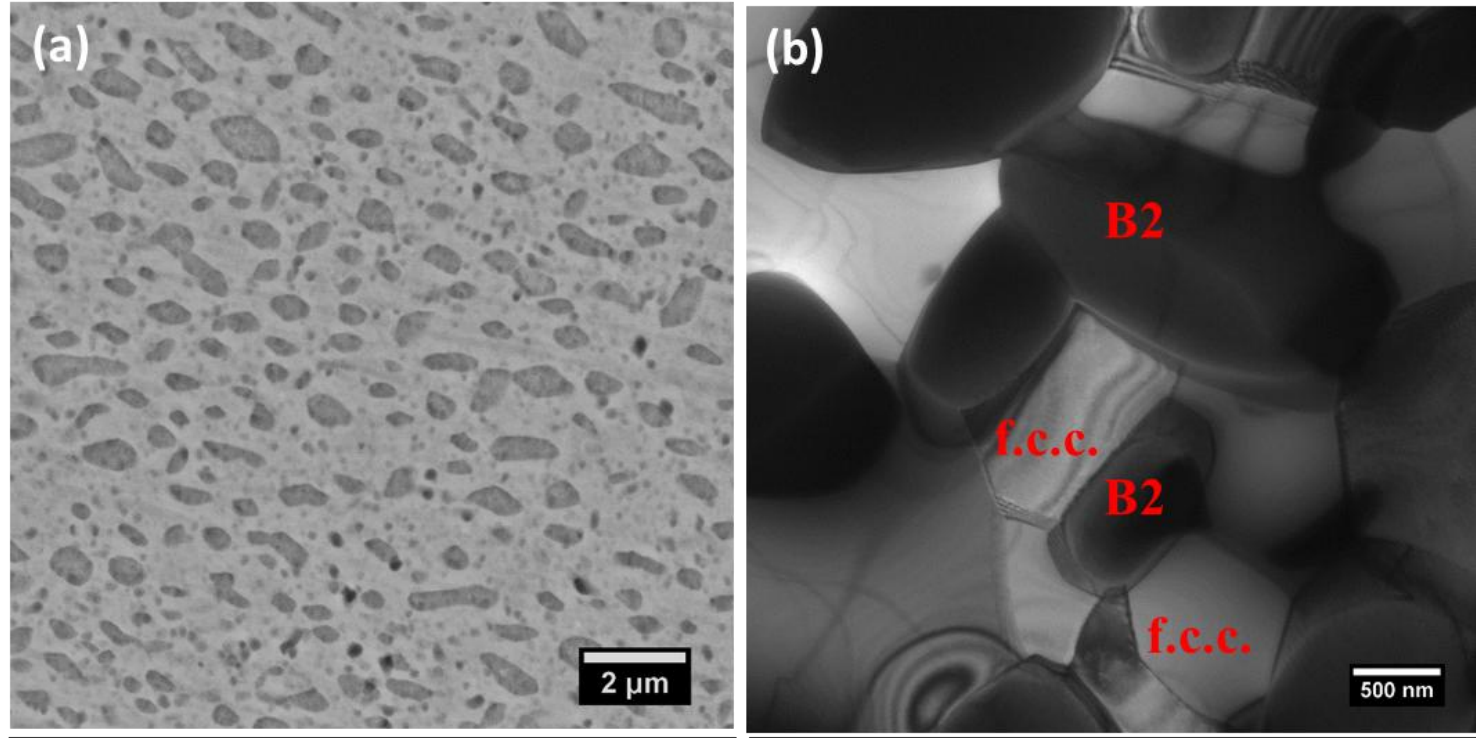

(c) f.c.c. ZA (111)

(d) B2 ZA (001)
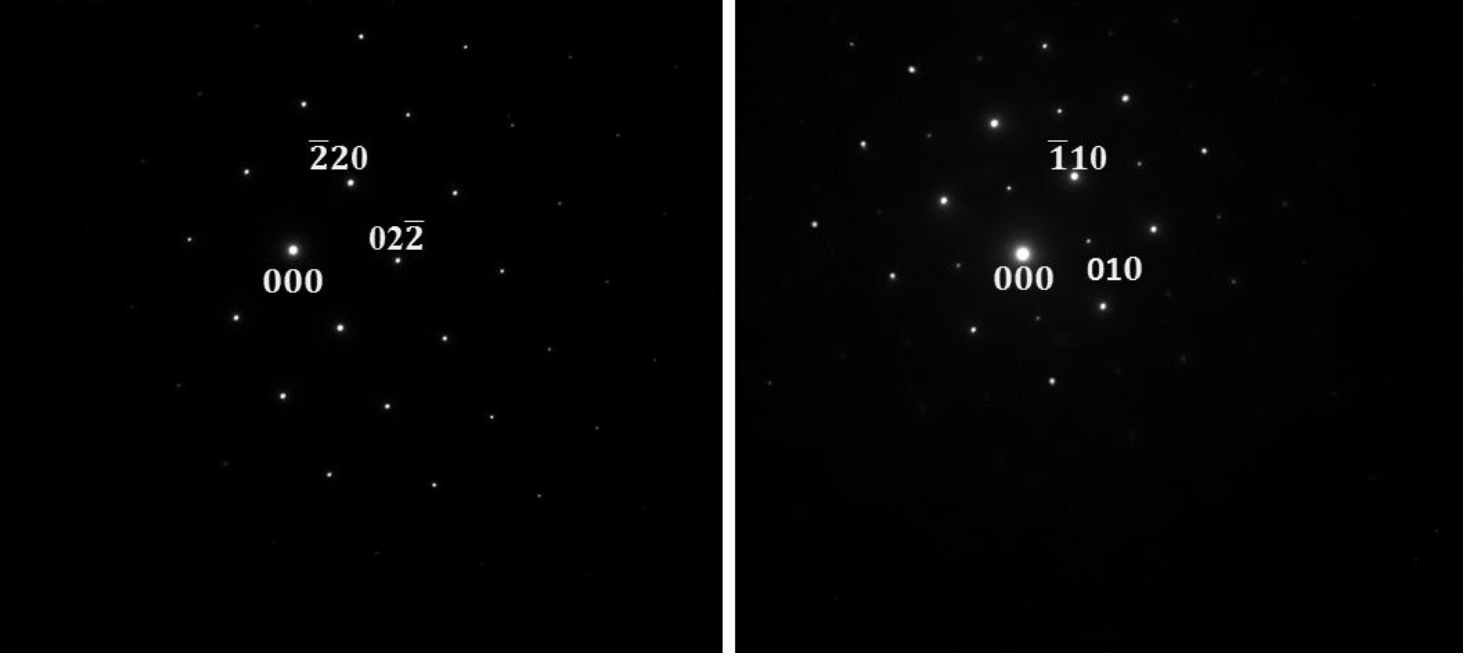

Figure 4. (a) BSE image (the lighter areas are the f.c.c. phase), and (b) bright field TEM image of $\mathrm{Fe}_{28.2} \mathrm{Ni}_{18.8} \mathrm{Mn}_{32.9} \mathrm{Al}_{14.1} \mathrm{Cr}_{6}$ cold rolled and annealed for $1 \mathrm{~h}$ at $1273 \mathrm{~K}$ showing equi-axed grains of the f.c.c. (light) and B2 (dark) phases. SAD patterns from (c) an f.c.c. grain, and (d) a B2 grain are also shown. The crystal structures of the grains marked in (b) were identified from their electron diffraction patterns. 


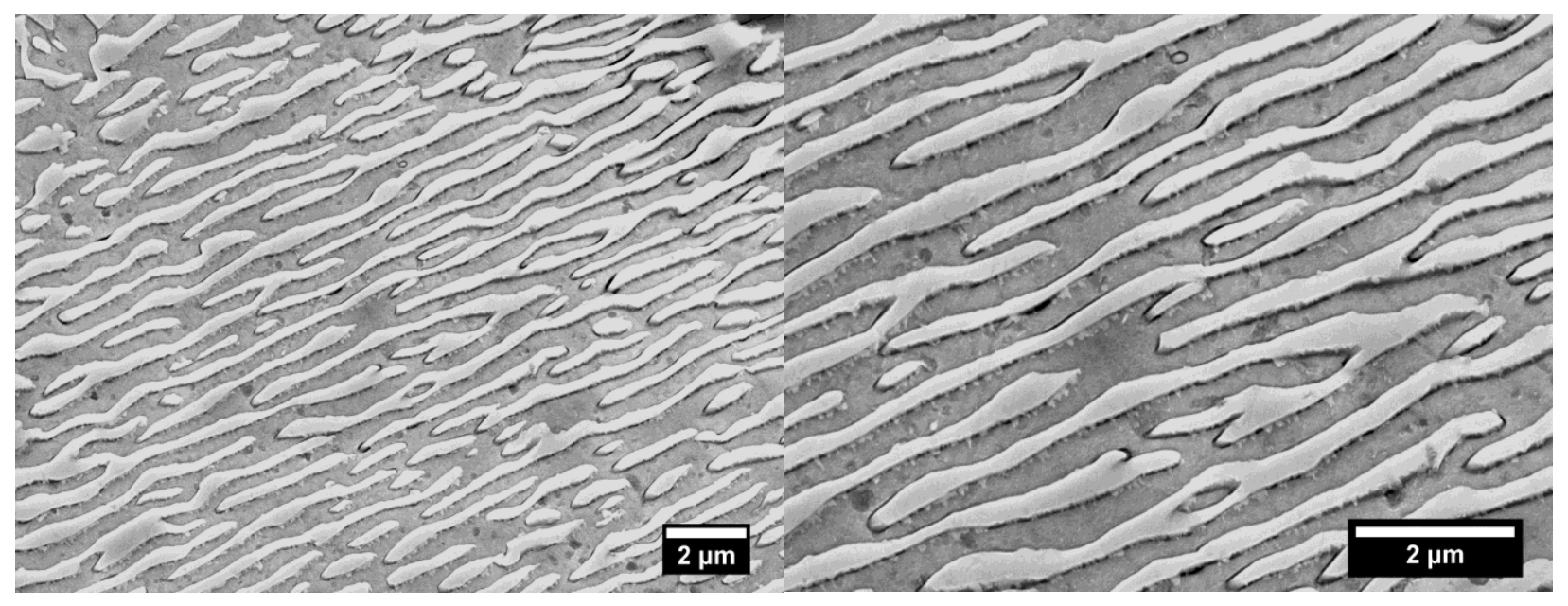

Figure 5. SE images of $\mathrm{Fe}_{28.2} \mathrm{Ni}_{18.8} \mathrm{Mn}_{32.9} \mathrm{Al}_{14.1} \mathrm{Cr}_{6}$ after annealing at $1273 \mathrm{~K}$ for $1 \mathrm{~h}$ : the lighter areas are the $\mathrm{B} 2$ phase. 


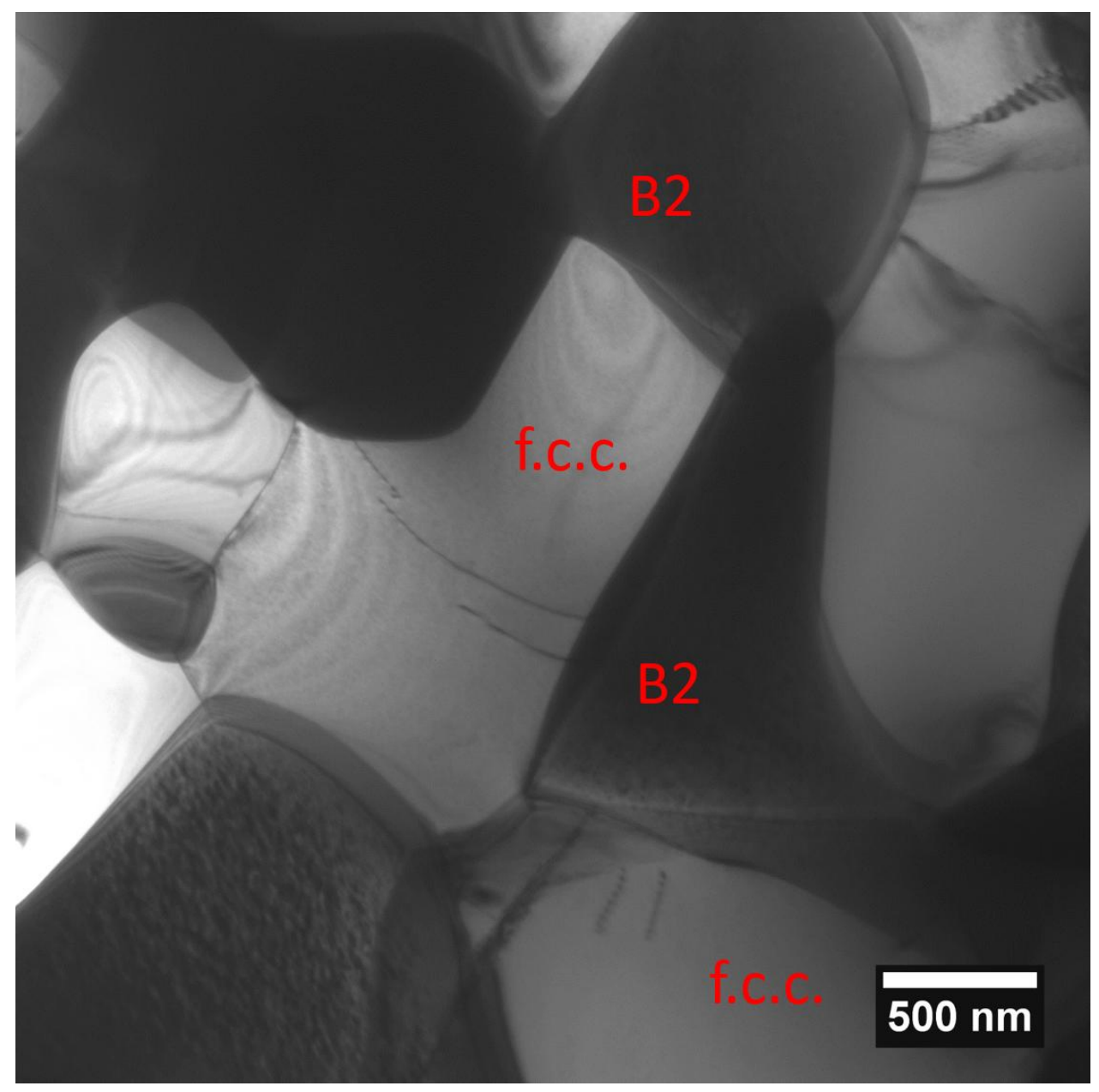

Figure 6. Higher magnification bright field TEM image of $\mathrm{Fe}_{28.2} \mathrm{Ni}_{18.8} \mathrm{Mn}_{32.9} \mathrm{Al}_{14.1} \mathrm{Cr}_{6}$ cold rolled and annealed for $1 \mathrm{~h}$ at $1273 \mathrm{~K}$ showing a few dislocations in the f.c.c. grains. 


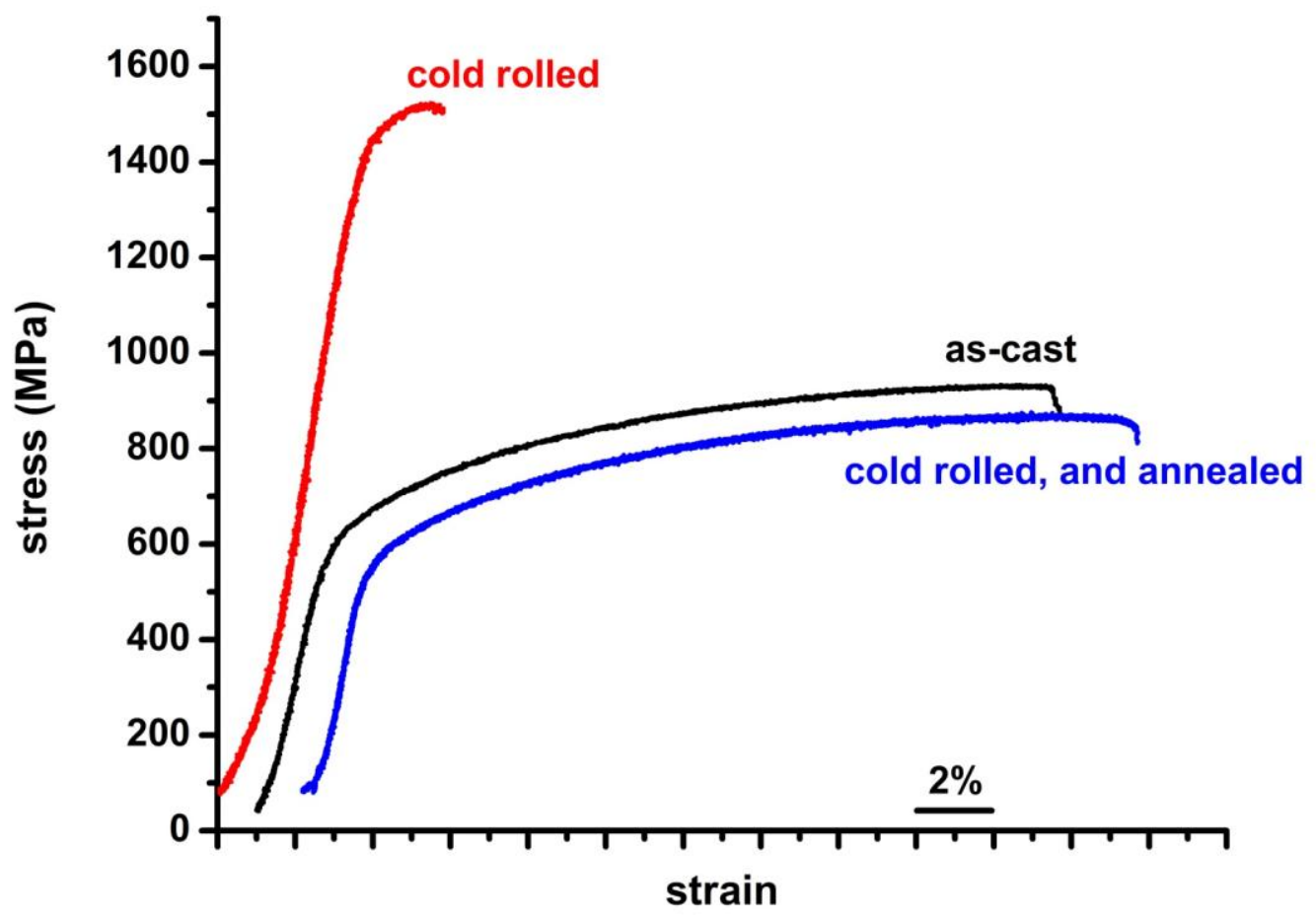

Figure 7. Typical stress-strain curves for as-cast, cold rolled, and recrystallized $\mathrm{Fe}_{28.2} \mathrm{Ni}_{18.8} \mathrm{Mn}_{32.9} \mathrm{Al}_{14.1} \mathrm{Cr}_{6}$. The curve for as-cast material is taken from [12]. 

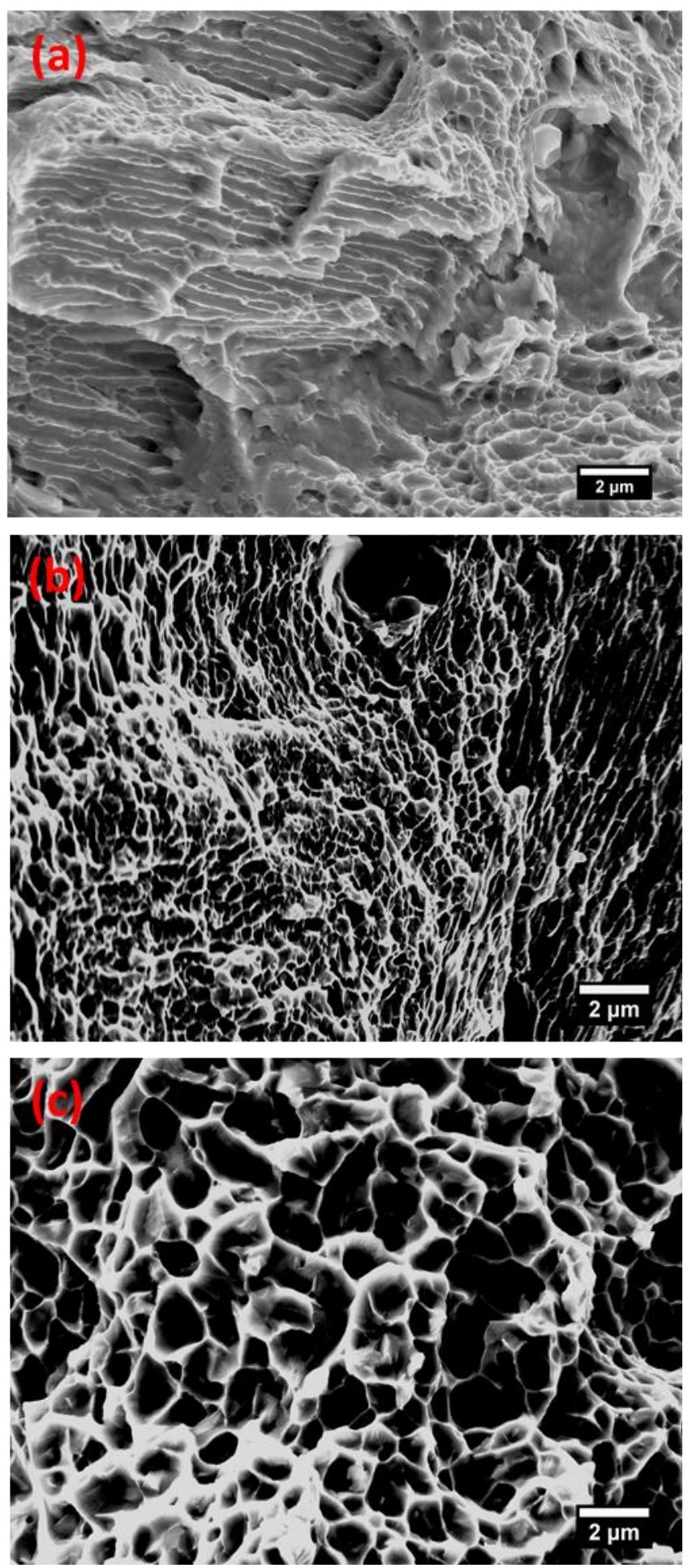

Figure 8. Secondary electron images showing the fracture surfaces of $\mathrm{Fe}_{28.2} \mathrm{Ni}_{18.8} \mathrm{Mn}_{32.9} \mathrm{Al}_{14.1} \mathrm{Cr}_{6}$ after tensile testing in (a) the as-cast state, (b) after cold-rolling, and (c) after recrystallization. 

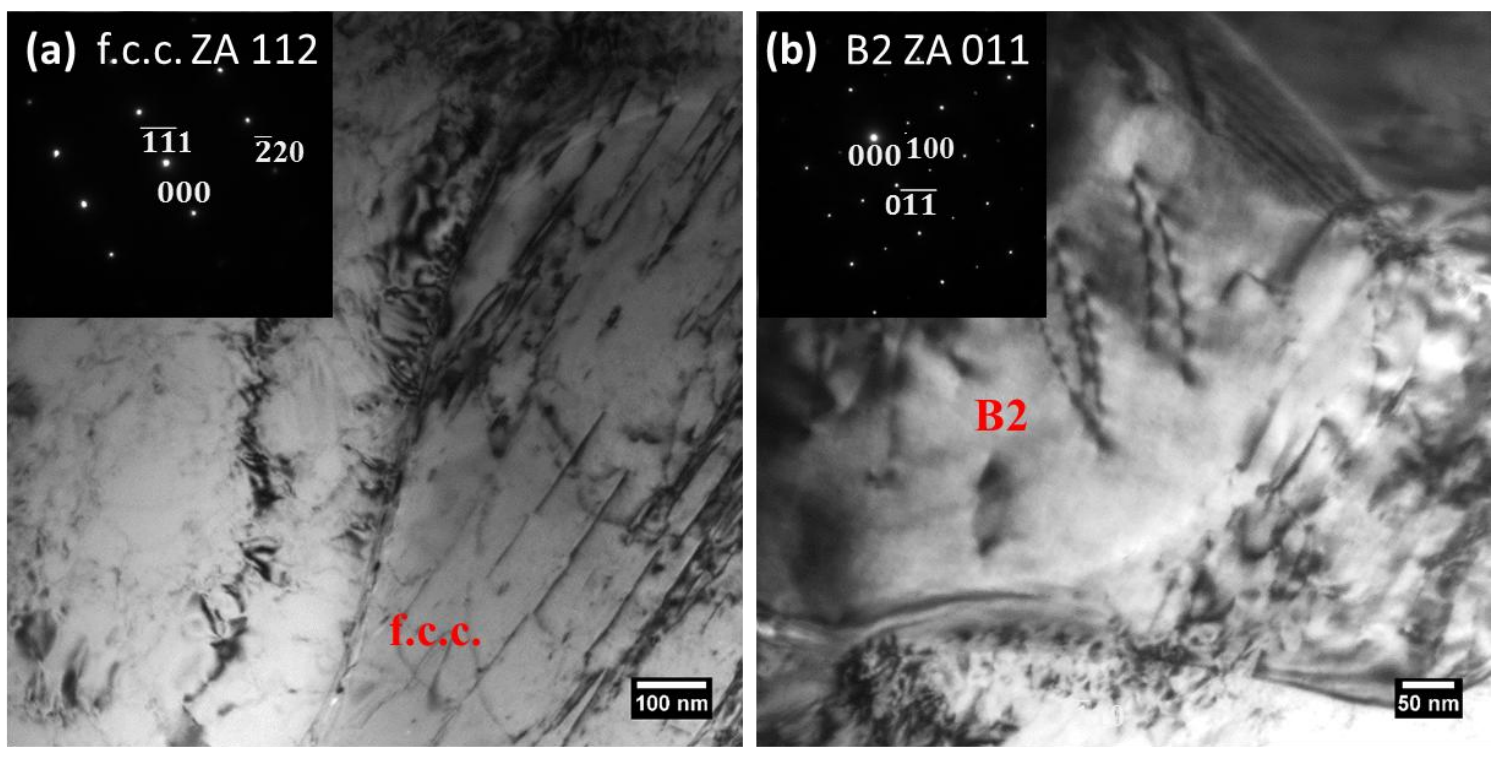

Figure 9. Bright Field TEM images from (a) the f.c.c. phase, and (b) the B2 phase of recrystallized $\mathrm{Fe}_{28.2} \mathrm{Ni}_{18.8} \mathrm{Mn}_{32.9} \mathrm{Al}_{14.1} \mathrm{Cr}_{6}$ after straining to failure, accompanied by SAD patterns from the corresponding phases. Dislocations were present in both the f.c.c. and B2 phases. 
Graphical Abstract

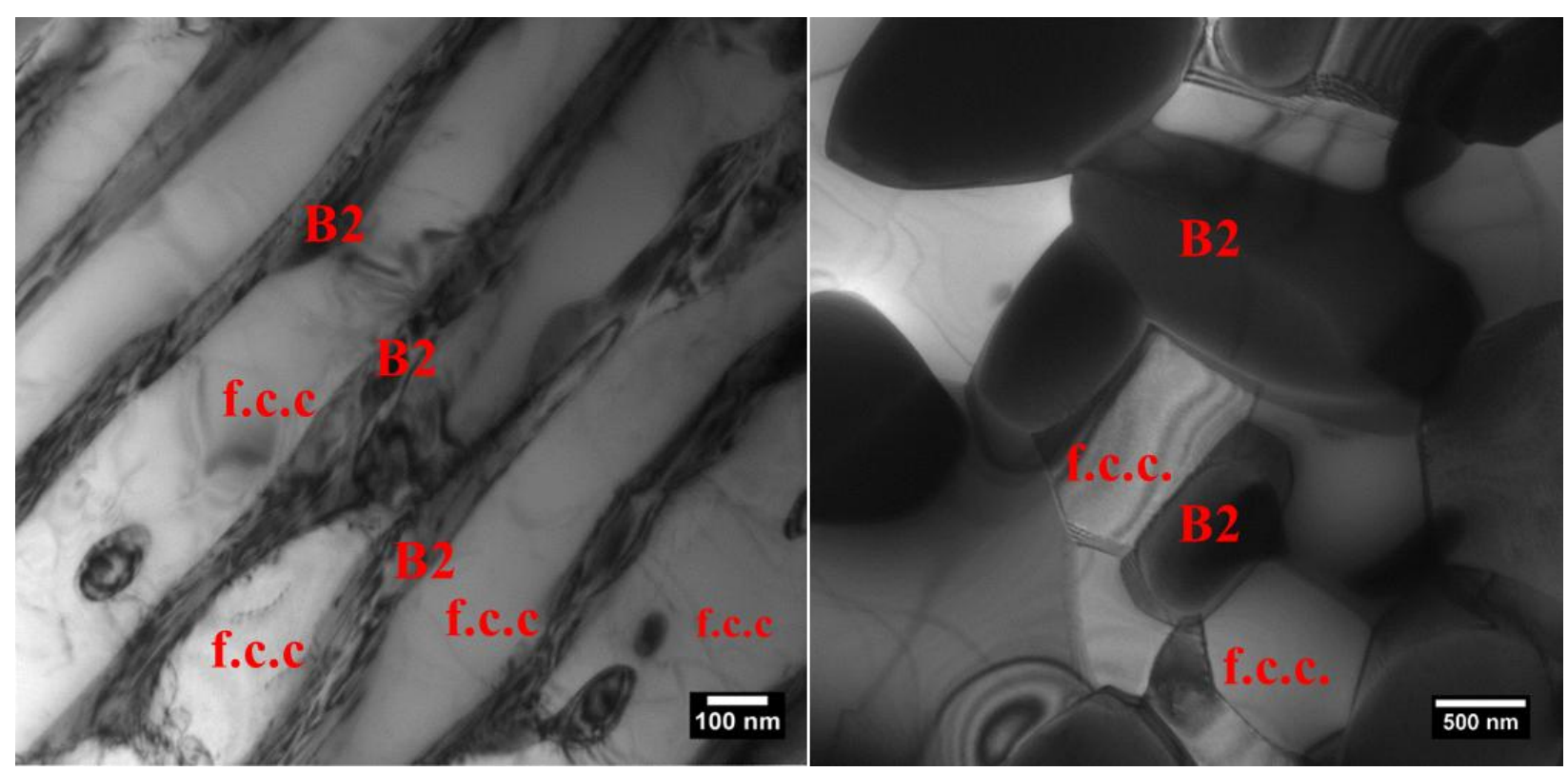

